\title{
Microstructural Characteristics and Mechanical Properties of 2205/AZ31B Laminates Fabricated by Explosive Welding
}

\author{
Yan Li and Zhisheng $\mathrm{Wu}$ * \\ School of Material Science and Engineering, Taiyuan University of Science and Technology, 66 Waliu Road, \\ 030024 Taiyuan, China; yanlityust@163.com \\ * Correspondence: zswu@tyust.edu.cn; Tel.: +86-0351-216-1126 \\ Academic Editor: Ian Baker \\ Received: 26 February 2017; Accepted: 28 March 2017; Published: 4 April 2017
}

\begin{abstract}
A bimetal composite of 2205 duplex stainless steel and AZ31B magnesium alloy was cladded successfully through the method of explosive welding. The microstructural characteristics and mechanical properties of 2205/AZ31B bimetal composite are discussed. The interface of 2205/AZ31B bimetallic composite was a less regular wavy morphology with locally melted pockets. Adiabatic shear bands occurred only in the AZ31B side near explosive welding interface. The microstructure observed with EBSD showed a strong refinement near the interface zones. Line scan confirmed that the interface had a short element diffusion zone which would contribute to the metallurgical bonding between 2205 duplex stainless steel and AZ31B magnesium alloy. The value of micro-hardness near the bonding interface of composite plate increased because of work hardening and grain refinement. The tensile shear strength of bonding interface of 2205/AZ31B composite was 105.63 MPa. Tensile strength of 2205/AZ31B composite material was higher than the base AZ31B. There were two abrupt drops in stress in the stress-strain curves of the 2205/AZ31B composite materials.
\end{abstract}

Keywords: 2205 duplex stainless steel; AZ31B magnesium alloy; explosive welding; interface microstructure; mechanical properties

\section{Introduction}

Bimetal composites can utilize the advantages of two materials, obtaining a property that a single metal cannot satisfy. Thus, bimetal composites have broad development prospects and are becoming a popular research field in material science [1]. Typical bimetal composites, such as stainless steel/carbon steel [2], titanium/steel [3], titanium/aluminum [4] and so on, have been used in a wide range of industrial fields. Magnesium alloys have wide application prospects in the automotive and transportation industries due to their low weight, high specific strength and good castability [5]. However, magnesium alloys have the intrinsic drawbacks of poor corrosion resistance and low formability [6], which limit the application of magnesium alloys. It is well known that stainless steel (STS) exhibits excellent corrosion resistance and mechanical strength, which makes it perfect for use in a wide range of industrial fields [7]. Therefore, a bimetallic macro-scale composite material comprised of magnesium alloys and stainless steels cannot only protect from the corrosion of magnesium alloys but also utilize the strength of stainless steels [8]. Besides, the characteristics of earthquake resistance and wave absorption of magnesium alloys $[9,10]$ can make up for the deficiency of stainless steels in these areas. Stainless steels can also increase the strength, wear resistance and impact resistance of magnesium alloys [11]. We know that $\mathrm{Fe}$ and $\mathrm{Mg}$ elements are incompatible according to $\mathrm{Mg}$-Fe binary alloy phase diagram [12]. Because of the difference in melting point (TM AZ31 $=630{ }^{\circ} \mathrm{C}$ and 
TM $2205=1455{ }^{\circ} \mathrm{C}$ ), it is impossible to use fusion welding to melt these two kinds of metal at the same time [13]. Consequently, bonding between STS and Mg alloys is considerably restricted.

In recent years, many investigators have been involved in the study of the bonding process of magnesium alloy and steel. A variety of joining techniques have been attempted to achieve the joining of magnesium and steel. Elthalabawy and Khan [13] investigated the use of liquid phase forming interlayers to bond AZ31 to 316L. The experimental result indicated that stainless steel and magnesium alloy were successfully joined by using pure $\mathrm{Cu}$ interlayer at a eutectic temperature of $530{ }^{\circ} \mathrm{C}$ and pure $\mathrm{Ni}$ interlayer at a eutectic temperature of $510{ }^{\circ} \mathrm{C}$. Bikulcius et al. [14] attempted to improve the corrosion resistance of magnesium alloy by sputter coating with stainless steel. Yuan et al. [15] studied diffusion-brazing technique of magnesium alloy and stainless steel. AZ31 and 304L were bonded by the diffusion-brazing process using pure copper as an intermediate layer. Miao et al. [16] investigated the mechanical properties and microstructure of AZ31 and Q235 welded joints by laser penetration brazing. They discovered that joining magnesium alloy to steel was defect-free when the laser offset was $0.6 \mathrm{~mm}$ and the tensile strength reached a maximum of $185 \mathrm{MPa}$. Wei et al. [17] designed a stirring pin to obtain magnesium alloy and stainless steel welding joint made using friction stir lap welding. Lee et al. [8] fabricated Mg-Al-stainless steel 3-ply clad sheet using the rolling bonding process. The above methods which require the use of high-end devices and an intermediate layer are high-cost and complex operations. In addition, these methods easily form intermetallic compounds at high temperatures $[8,18]$.

Explosive welding (EXW) is a very useful technology to directly clad similar materials and dissimilar materials, as a large combination of metal plates is impractical to bond with conventional welding techniques [1,19]. Explosive welding can facilitate the formation of a joint at lower temperatures and restrain formation of the brittle intermetallic phases [20]. Similar and dissimilar metal and alloy combinations can be welded by using explosive welding techniques [1-4]. However, there is no report on explosive welding of magnesium alloy to stainless steel so far.

In the present investigation, 2205 stainless steel was explosive welded to AZ31B magnesium alloy. Mechanical properties such as micro-hardness, tensile shear strength and tensile strength of explosively welded composite plate were evaluated. The microstructural morphology and the elemental distribution near the weld interface were investigated by means of optical microscope $(\mathrm{OM})$, scanning electron microscope (SEM) and Energy Dispersive Spectrometer (EDS). The aim of this study is to produce a composite and to examine the joining ability of 2205 stainless steel and AZ31B magnesium alloy with explosive cladding. As a result, this study is a new contribution in the field of Mg-steel laminated composite manufacturing.

\section{Experimental Procedures}

\subsection{Materials}

In this study, 2205 stainless steel sheet and AZ31B magnesium alloy sheet were used for explosive cladding. 2205 stainless steel sheet was selected as the cladding layer because of its superior corrosion resistance, AZ31B magnesium alloy sheet was chosen as parent sheet. The dimensions of 2205 and AZ31B sheets used in this study were $1000 \mathrm{~mm} \times 800 \mathrm{~mm} \times 2 \mathrm{~mm}$ and $1000 \mathrm{~mm} \times 800 \mathrm{~mm} \times 3 \mathrm{~mm}$, respectively. The chemical compositions of 2205 and AZ31B are tabulated in Tables 1 and 2, respectively.

Table 1. The chemical composite (wt. \%) of the 2205 stainless steel.

\begin{tabular}{cccccccccc}
\hline Element & C & Si & Cr & Mn & Ni & Mo & P & S & Fe \\
\hline Wt. $\%$ & 0.021 & 0.56 & 22.59 & 1.13 & 5.29 & 3.45 & 0.018 & 0.001 & Balanced \\
\hline
\end{tabular}


Table 2. The chemical composite (wt. \%) of the AZ31B magnesium alloy.

\begin{tabular}{ccccccc}
\hline Element & Mn & Zn & Si & Fe & Al & Mg \\
\hline Wt. $\%$ & 0.63 & 1.10 & 0.10 & 0.05 & 3.02 & Balanced \\
\hline
\end{tabular}

\subsection{Explosive Cladding Process}

The explosive welding process was carried out using a parallel arrangement as schematically shown in Figure 1. The surface of the flyer plate and base plate were polished with $800 \# \mathrm{SiC}$ paper to remove the impurities. The upper surface of the flyer plate was coated with thin butter. The explosive material was flat above the butter layer and was sealed with a hard paper box whose dimensions were the same as the flyer plate. A detonator was inserted into explosive material to trigger an explosion and was placed at the edge of the flyer plate. The explosive material in this study was a mixed ammonium nitrate explosive. The detonation velocity was about $2200-2500 \mathrm{~m} / \mathrm{s}$. The explosive thickness was $25 \mathrm{~mm}$. The initial gap between the flyer plate and basic plate was about $5 \mathrm{~mm}$. Explosive welding parameters were chosen on the basis of empirical formulas [21].

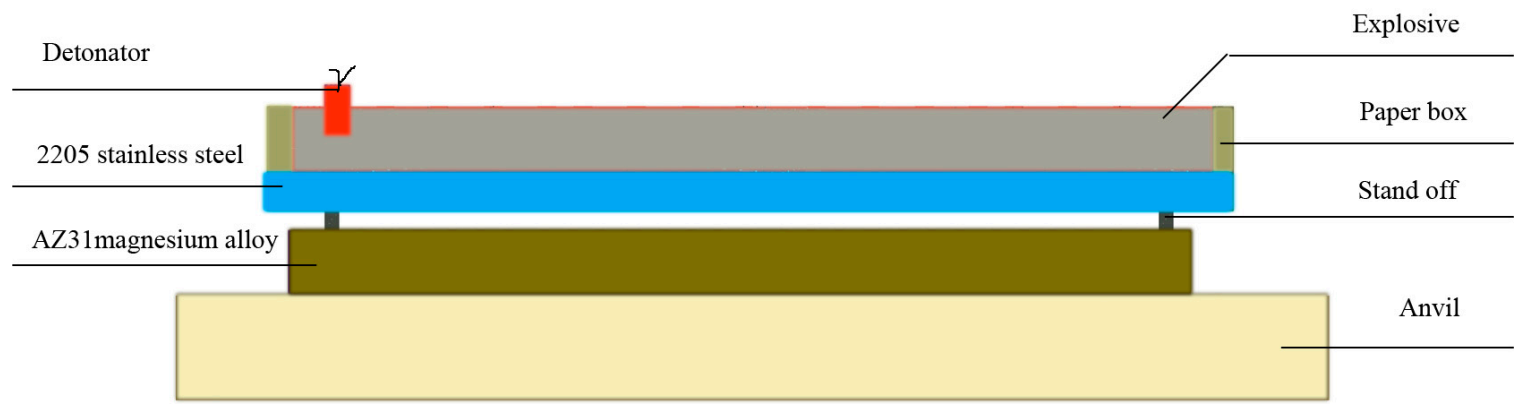

Figure 1. Experimental setup of explosive welding.

\subsection{Microstructural Work}

Specimens for microstructural observations of 2205/AZ31B composite plate were prepared by standard metallographic techniques. The metallographic samples were cut parallel to the explosion direction from cross-section of the bimetallic composite plate. The AZ31B base plate was etched with an etchant consisting of $1 \mathrm{~mL}$ of $\mathrm{HNO}_{3}, 1 \mathrm{~mL}$ of $\mathrm{CH}_{3} \mathrm{COOH}, 1 \mathrm{~g}$ of $\mathrm{C}_{2} \mathrm{H}_{2} \mathrm{O}_{4}$ and $150 \mathrm{~mL}$ of deionized water. The microstructure characterization was done using an optical microscope (KEYENCE VHX-2000 (KEYENCE, Osaka, Japan). The grain sizes around the interface were analyzed using Gemini Sigma 300/VP SEM (Carl Zeiss AG, Jena, Germany) equipped with an Electron Backscattered Diffraction (EBSD) system. EDS X-ray analysis using a Gemini Sigma 300/VP SEM was used to study the chemical variations across the 2205/AZ31B composite plate interface.

\subsection{Mechanical Test}

To evaluate the mechanical properties of explosively welded 2205/AZ31B composite materials, a series of mechanical tests were carried out. All specimens were processed by the wire electrical discharge machining with low-speed (WEDM-LS). The microhardness values near the interface were measured on a microhardness machine (HV-1000). During the test, $100 \mathrm{gf}$ load and $15 \mathrm{~s}$ holding time were applied. Different points were measured across the interface. Tensile tests were carried out for 2205 base metal and AZ31B base metal, and 2205/AZ31B composite material. The dimension of 2205/AZ31 composite tensile test specimen was shown in Figure 2. Tensile-shear test specimen was presented in Figure 3. The tensile shear test was carried out such that the tensile shear loading was assured along the bond interface. Fractography studies were conducted using a Gemini Sigma 300/VP SEM. 


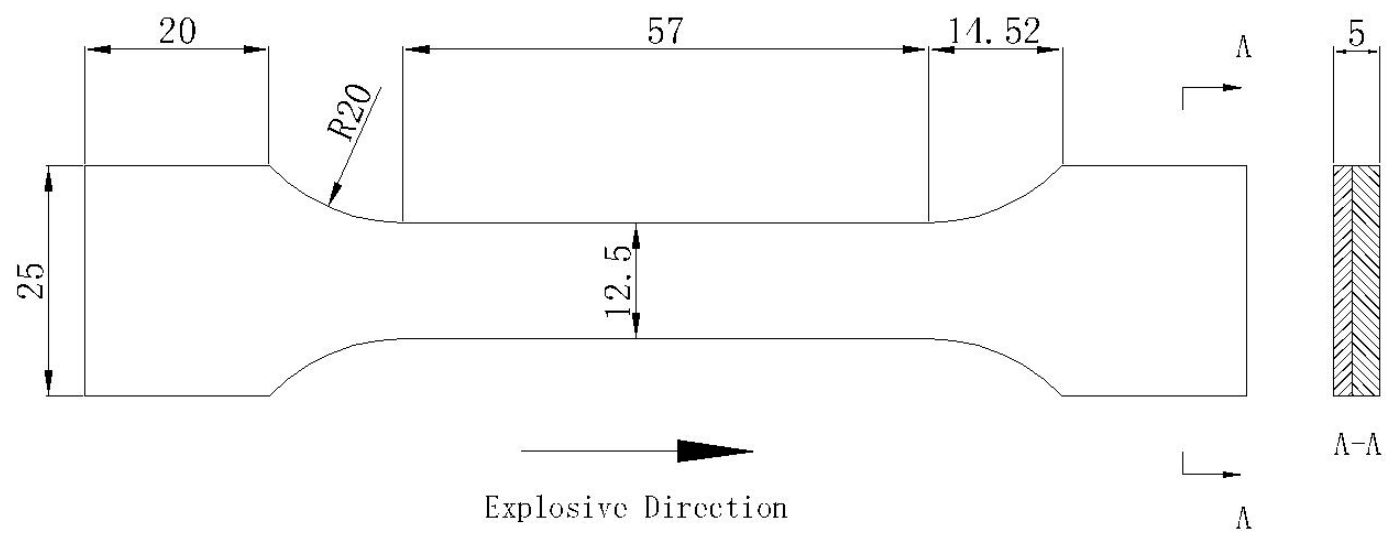

Figure 2. The dimension and orientation of tensile test specimen of 2205/AZ31B composite material (mm).
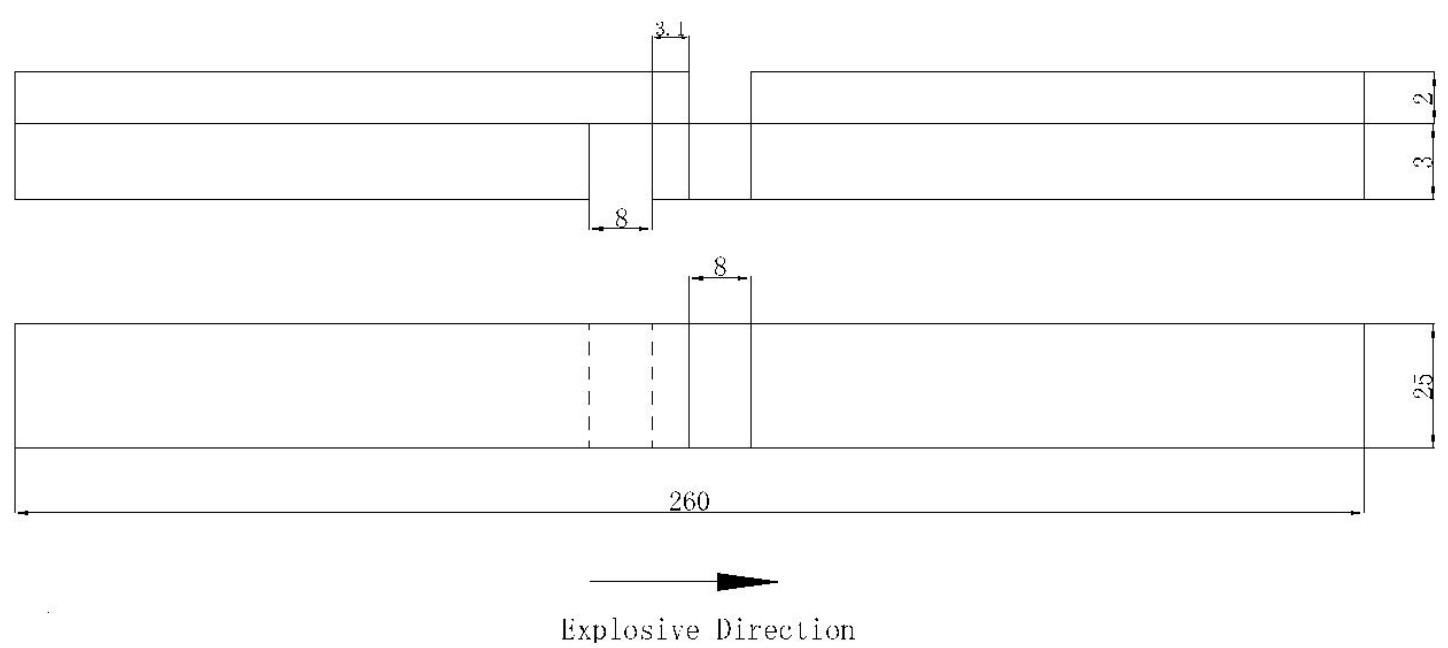

Figure 3. Schematic showing specimen dimensions for tensile shear test (mm).

\section{Results and Discussion}

\subsection{Macro Morphology of Composite Plate}

A photograph of the explosively welded 2205/AZ31B composite plate is shown in Figure 4a. The surface of the composite plate showed no macroscopic crack except for small zones near their edges. The bad bond region was approximately $25 \mathrm{~mm}$ wide, which was attributed to unstable explosive energy at the beginning stages. The boundary position was not bonded as seen in Figure $4 \mathrm{~b}$. A similar result was reported by Mastanaiah et al. [22]. The composite plate-removing crack boundary was subjected to ultrasonic inspection according to ASTM A578M. The inspection result indicated that bonding interface was fault-free. Figure $4 \mathrm{c}$ presents a photograph of the cut section of the composite sheet. It was observed that the welding quality was sound, no crack and delamination were present. This demonstrated that explosive welding was an applicative technique to bond 2205 stainless steel and AZ31 magnesium alloy plates. 


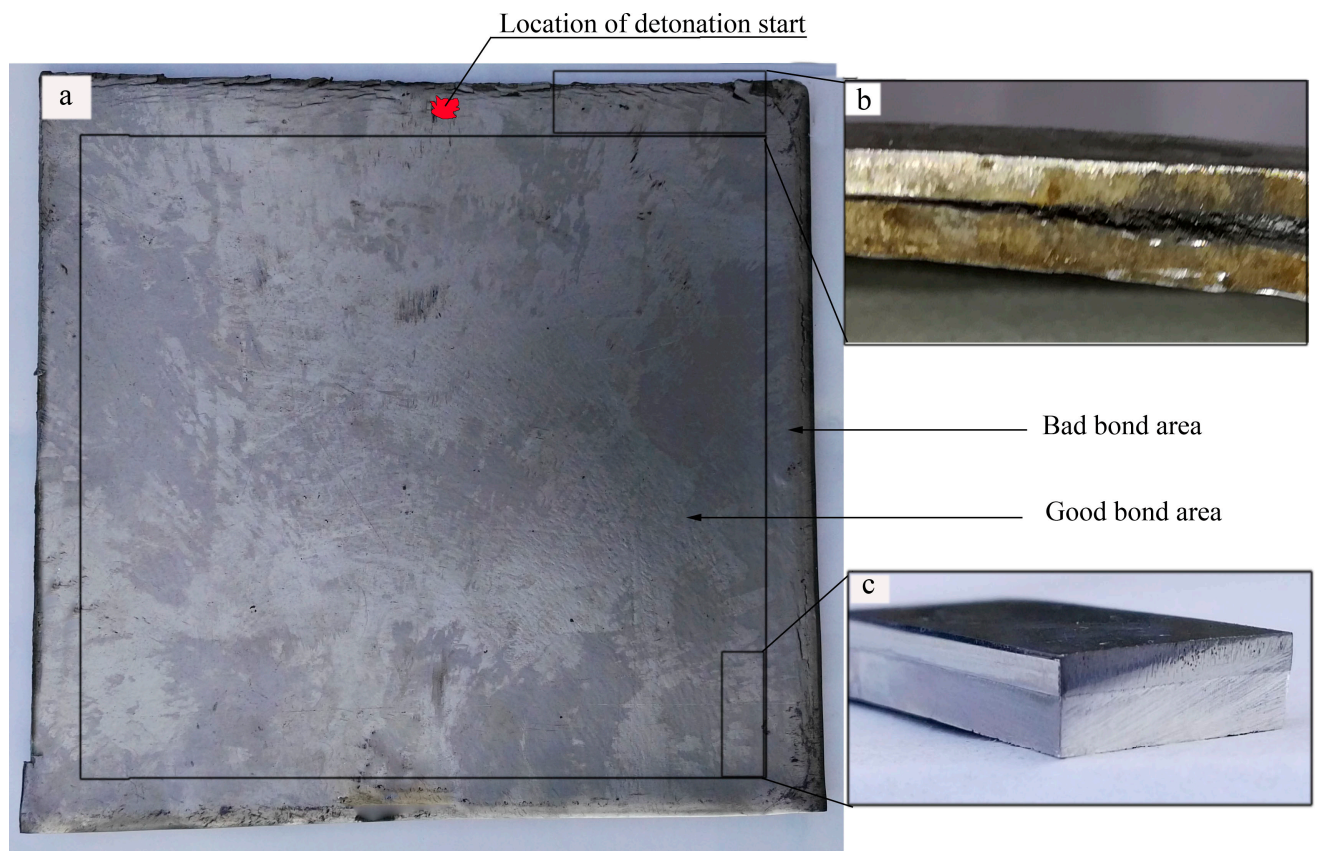

Figure 4. The 2205/ AZ31 composite plate achieved by explosive welding. (a) Top view, top layer 2205, (b) Cross-section at the border, (c) Cross-section at the good bond area.

\subsection{Morphology near the Interface}

Figure 5a is a cross-section of 2205/AZ31B bimetallic composite. According to the macroscopic morphology, the 2205/ AZ31B bimetallic composite had an almost-straight bonding interface. Based on the explosive weldability window theory [23], straight, wavy and melting interfaces could be formed after the explosive welding. The interface morphology is related to welding process parameters and the properties of materials. In work of Durgutlu et al. [24], the bonding interface transformed from straight to wavy with the increasing of explosive ratio and stand-off distances. No pores and cracks were observed near the interface from Figure 5a. In addition, the presented microstructure of the 2205/AZ31B interface showed that local melting zones occurred on the magnesium alloy side, resulting from the low melting point of magnesium alloy compared to stainless steel.

It can also be seen from Figure 5a that there were many adiabatic shear bands (ASBs) originating from the interface as indicated by arrows and disappearing with increasing distance from the bonding interface on the AZ31B side near the interface. Magnesium alloys are well known to easily form ASB under high strain rates such as explosive shocking, ballistic impact and high-velocity shaping [19]. It was reported that the ASB was a special case of thermoplastic instability favored by high rates of compressive strain [25]. In the explosion welding process, the strong explosion shock loading caused the high temperature, high pressure and high shear strain near the interface. The explosion time was very short, insufficient time for the heat to dissipate before thermal softening occurred, which contributed to promoting the development of ASB. No ASB was observed on the 2205 stainless steel side. Magnesium alloy (h.c.p.) had a limited slip system compared to 2205 stainless steel. Due to the crystal structure difference, stainless steel had a larger ability to accommodate the strain by dislocation movement than magnesium alloy, this was one of the reasons why ASB occurred only on the AZ31 side and not on the 2205 side. Figure $5 \mathrm{~b}$ is a high-magnification photomicrograph of the ASB structures. It was evident that the ASB structures had fine grains. Yang et al. [26,27] reported that dynamic recrystallization was the formation mechanism of ASB after explosive welding. In high-temperature conditions, new grains nucleated and grew inside the grain. As a direct consequence, the microstructure of ASB refined. 




Figure 5. Optical morphology image of explosion bond. (a) an overall image of the interface macrostructure, (b) a magnified image showing the adiabatic shear band (ASB) structure in position A in Figure 5a.

Figure 6a presents the EBSD analysis results across the 2205/AZ31B interface, and the grain size statistics for different crystals are shown in Figure $6 \mathrm{~b}-\mathrm{d}$. Finer grain is colored blue. As shown in Figure 6a, the blue grains are distributed near the interface, with the grains around the interface obviously having been refined after explosive welding. This is because the temperature and pressure at the bonding interface are fiercely raised during the explosive welding process, and remain so for a while $[28,29]$. Though the high temperature and pressure time are extremely short, they created an annealing effect. Thus, finer grains are formed around interface due to the rapid cooling speed. 


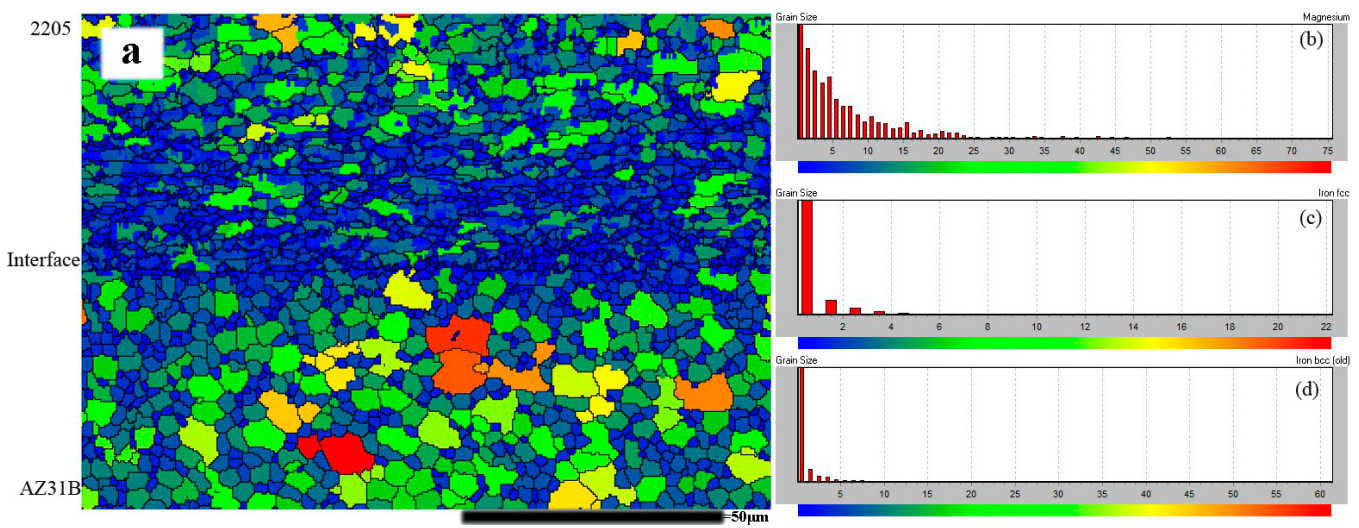

Figure 6. Electron Backscattered Diffraction (EBSD) map showing the interface micromorphology. (a) EBSD map showing the grain size distribution, (b) Grain size statistics for hcp crystals, (c) Grain size statistics for fcc crystals, (d) Grain size statistics for bcc crystals.

\subsection{SEM Morphology and EDS Analyses near the Interface}

Figure 7 shows the SEM micrograph of the 2205/AZ31B interface. It can be observed that the bonding interface presents a less regular, wavy morphology. Mousavi and Sartangi [3] have explained the wavy forming mechanism of explosive welding interface. The less regular wavy morphology is the result of the large differences in both melting temperature and density between 2205 and AZ31B $[4,30]$. The wave is symmetric in the literature reported for similar materials, such as in the welding of aluminium (Al to Al) [31] and steel (stainless steel to carbon steel) [2,7]. Furthermore, as illustrated in Figure 7, irregularly distributed molten metal is observed in the vicinity of the wave-like interface, which is due to instabilities induced by the explosion. It should be noted in Figure 7 that initial oxides covering in the interface did not exist at the interface after the explosive welding. After the detonation the stainless steel flyer plate was accelerated towards the magnesium alloy plate, the jetting formed between the two plates. It removed the initial oxides or impurities from the surface of two materials, which were also described in many early reports [4,32]. The existence of such oxide film was detrimental in other connection methods such as resistance welding [33] or diffusion bonding [34], as it could decrease the bond strength of joints.

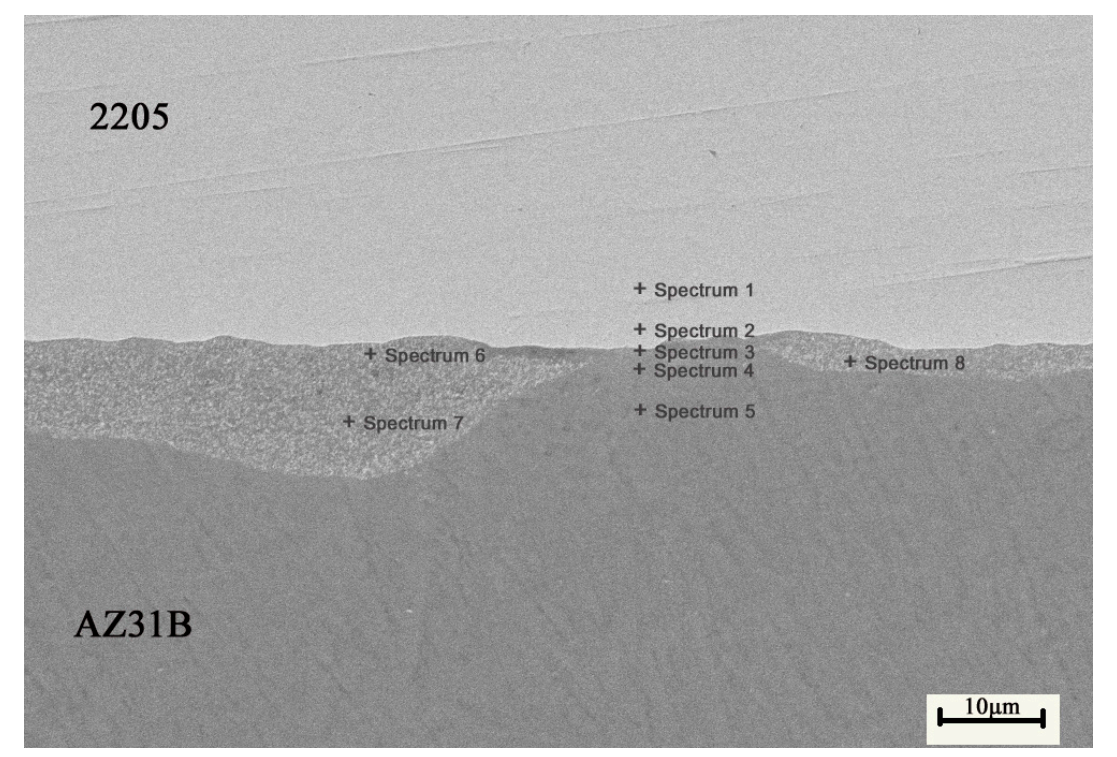

Figure 7. Scanning electron microscope (SEM) image near the interface including melt zones. 
In order to discuss the distribution of elements across the bonding interface, the representative concentration profiles of $\mathrm{Fe}, \mathrm{Cr}, \mathrm{Ni}$ in the 2205 stainless steel and $\mathrm{Mg}, \mathrm{Al}$ in the AZ31B are shown in Figure 8 . The line scan shows that there exists a thin diffusion layer in the bonding interface. But the concentration variations of $\mathrm{Cr}, \mathrm{Ni}$ and $\mathrm{Al}$ are difficult to reveal in the line scan because of their low concentrations. Elemental mutual diffusion indicates that metallurgical bonding of 2205 stainless steel and AZ31B magnesium alloy was achieved by explosive welding. The explosive welding process [1-4] is a "cold welding" process, and the explosion time is instantaneous (approximately $10^{-6} \mathrm{~s}$ ), so there is not enough time to form a thick diffusion layer and intermetallics. This is different from liquid phase bonding in which intermetallic compounds are formed by atomic interactions as a result of a long heating time [13].

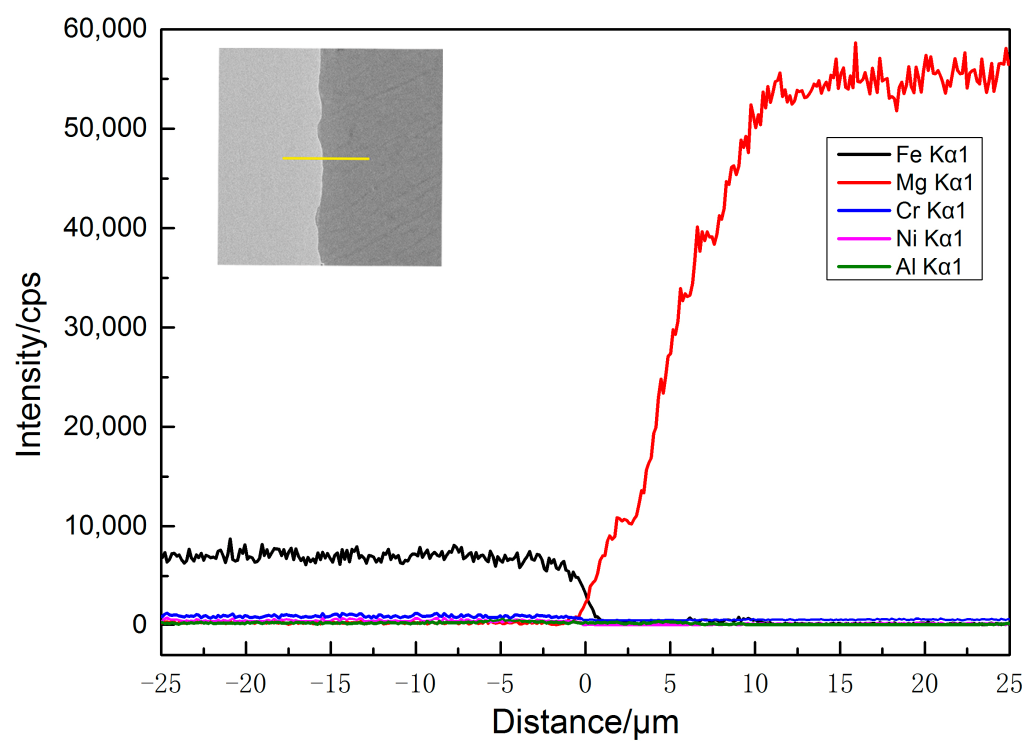

Figure 8. Energy Dispersive Spectrometer (EDS) line scan across the interface as indicated by line in inset.

Figure 9 shows the EDS spectrum images of representative points. Quantitative analysis of the chemical compositions near the interface are listed in Table 3. The chemical composition near the interface is not homogeneous as it varies depending on the EDS-analyzed zones in Figure 7. The variation trend of the chemical composition also indicates that a thin diffusion layer appears near the interface. The chemical compositions at point 1 and point 5 are in agreement with the base metals as listed in Tables 2 and 3. Specifically, the chemical compositions at points 6 to 8 in the local melted zone largely consist of $\mathrm{Mg}$, whereas relatively high Fe contents are also identified. The low melting point contributes to the preferential melting of magnesium alloy. The Fe element ejected from the 2205 sheet during the impact was captured in melting zones of magnesium alloy, resulting in a relatively high Fe content in melting zones. According to the Fe-Mg phase diagram [12], Fe and Mg elements are incompatible and cannot form any intermetallic compound. It is speculated that a non-equilibrium solid solution is formed near the interface through the Fe-Mg immiscible system [17]. The explosive welding process deviates a long way from equilibrium conditions [4]. During the explosive welding process, local high pressure and high temperature occurred near the interface, followed by grain refinement, which prompted the fast diffusion tracks (grain boundaries) for elements. Besides, the high-density dislocations near the interface were formed at the interface of metals when the explosion happened [22]. The high-density dislocations would also provide a channel for element diffusion [2,35]. Similar findings were also observed by Wei et al. [17] in the friction stir welding of stainless steel to magnesium alloy. The authors concluded that the strong plastic deformation under the action of the FSW tool promoted the mutual diffusion of magnesium and iron in the Fe-Mg immiscible system. 

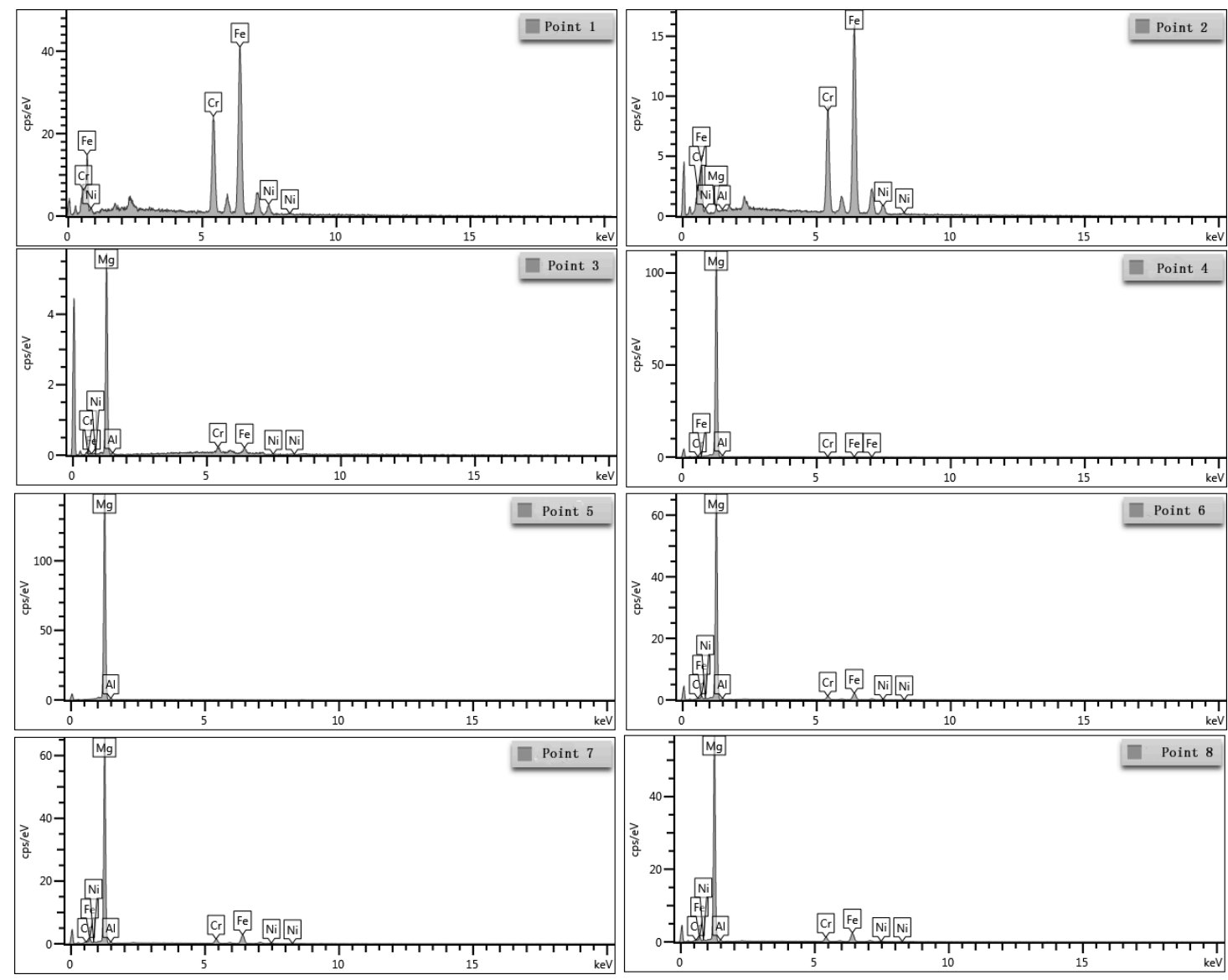

Figure 9. Energy Dispersive Spectrometer (EDS) spectrum images of representative points.

Table 3. Chemical compositions (Wt. \%) near interface as indicated in Figure 6.

\begin{tabular}{cccccc}
\hline Point & Fe & Cr & Ni & Mg & Al \\
\hline 1 & 69.80 & 23.80 & 6.40 & - & - \\
2 & 70.13 & 23.74 & 5.23 & 0.84 & 0.06 \\
3 & 10.72 & 6.61 & 0.61 & 81.54 & 0.52 \\
4 & 0.18 & 0.04 & 0.13 & 98.09 & 1.56 \\
5 & - & - & - & 97.58 & 2.42 \\
6 & 15.68 & 5.00 & 1.06 & 76.94 & 1.32 \\
7 & 12.88 & 4.41 & 1.29 & 80.21 & 1.21 \\
8 & 15.05 & 5.29 & 1.16 & 77.30 & 1.20 \\
\hline
\end{tabular}

\subsection{Microhardness Measurements}

Microhardness measurements were carried out across the 2205/AZ31B bonding interface to evaluate qualitatively the microstructural changes and mechanical property variations. Figure 10 showed the results of the microhardness across the 2205/AZ31B interface after explosive welding. Obviously, the microhardness values of 2205 near the interface had the highest value. The grain refinement near the interface led to an increase in hardness near the interface. In addition, because of the difference in the thermophysical properties between stainless steel and magnesium alloy, the residual stress contributes to the hardening effect near the interface [36]. The maximum microhardness value of 2205 near the interface was approximately $380 \mathrm{HV}$, which was approximately $51 \%$ higher than the microhardness of the 2205 base material. The microhardness of 2205 over $900 \mu \mathrm{m}$ away from the interface was $252 \mathrm{HV}$ which was similar to 2205 base material. In the magnesium alloy 
side, the microhardness reached a maximum $136 \mathrm{HV}$ near the collision surface. The microhardness of magnesium alloy over $300 \mu \mathrm{m}$ away from the interface was $96 \mathrm{HV}$ which was similar to magnesium alloy base material. It was evident that the microhardness of stainless steel near the bonding interface increased significantly, nevertheless microhardness on the side of magnesium alloy increased slightly. This was attributed to higher strain hardening of the stainless steel in comparison to the magnesium alloy. Another interesting observation in Figure 10 is that 2205 exhibited a wider hardening range than AZ31B, which was related to the higher softening temperature of stainless steel in comparison to magnesium alloy.

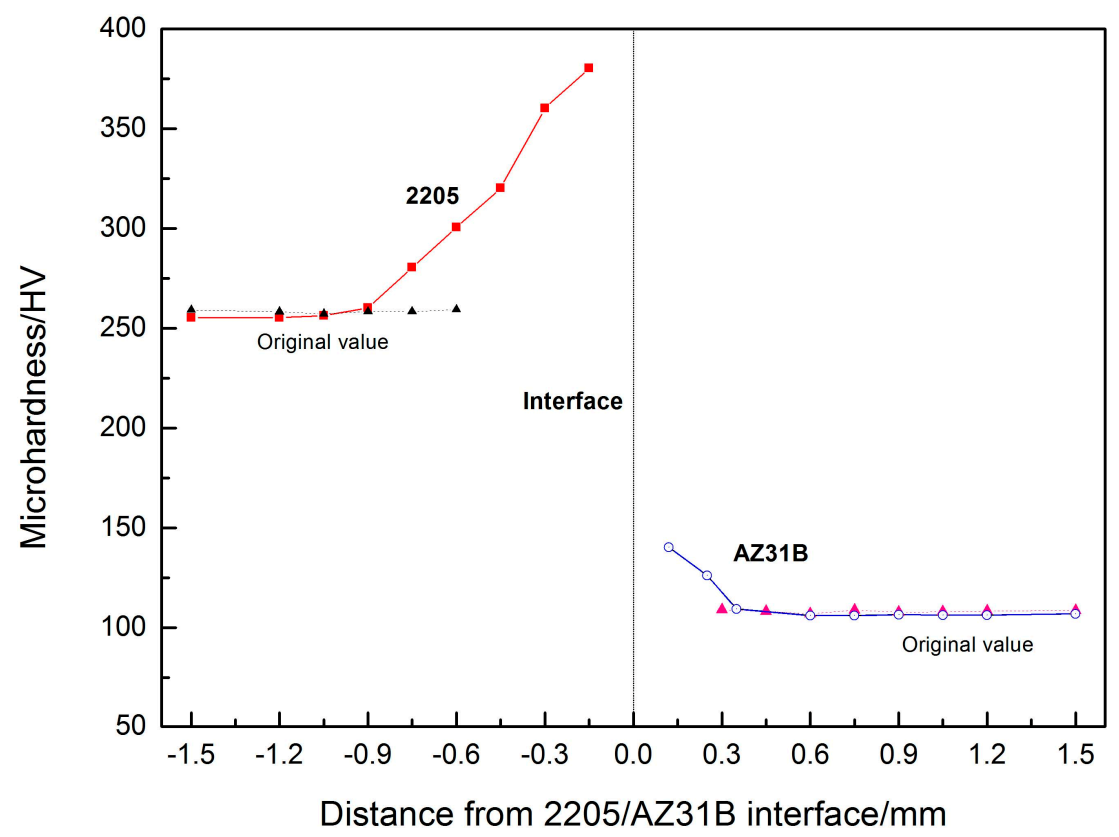

Figure 10. Microhardness values of the 2205/AZ31B explosively cladded joints.

\subsection{Tensile Strength Test Outcome}

In order to evaluate the tensile strength of 2205/AZ31B bimetal macro-composite, tensile tests were carried out for the 2205 base metal, AZ31B base metal and the 2205/ AZ31B composite material. Typical stress-strain curves are shown in Figure 11. The results of the tensile tests are also summarized in Table 4. In Figure 11, the results illustrate that the tensile strength of the 2205/AZ31B composite material is higher than the AZ31B base metal, which was the weaker material of the two dissimilar base materials. Two stress drops were seen from the stress-strain curves of the 2205/AZ31B composite material. According to the fracture macrostructure of composite materials shown in Figure 12b, a reduced stress phenomenon in the first stage of the tensile process was caused by the fracture of the AZ31 side. Soon afterwards, interface delamination occurred when stress increased, as seen in Figure 12c. In the end, the 2205 stainless steel fractured. The poor plastic deformation ability of magnesium alloy led to fracture from the AZ31 side in the first stress drop. It can clearly be seen from Figure 11 that there is a significant span in the second stage of the tensile process, which accompanied the intense necking effect in the 2205 side (Figure 12d). The good toughness of 2205 stainless steel resulted in a significant span in the second stage. The very high difference in toughness between magnesium alloy and stainless steel was the main reason for the delamination of the interface. The phenomenon of the two-stage fracture in tensile tests has been observed by other researchers who also studied the tensile properties of laminated composite materials [8]. Works carried out by Zhang et al. [28] on explosively joined $\mathrm{Mg}-\mathrm{Al}$ composite materials and Kim et al. [37] on roll joined tri-layered $\mathrm{Mg} / \mathrm{Al} /$ stainless steel clad plate had also shared similar results. 


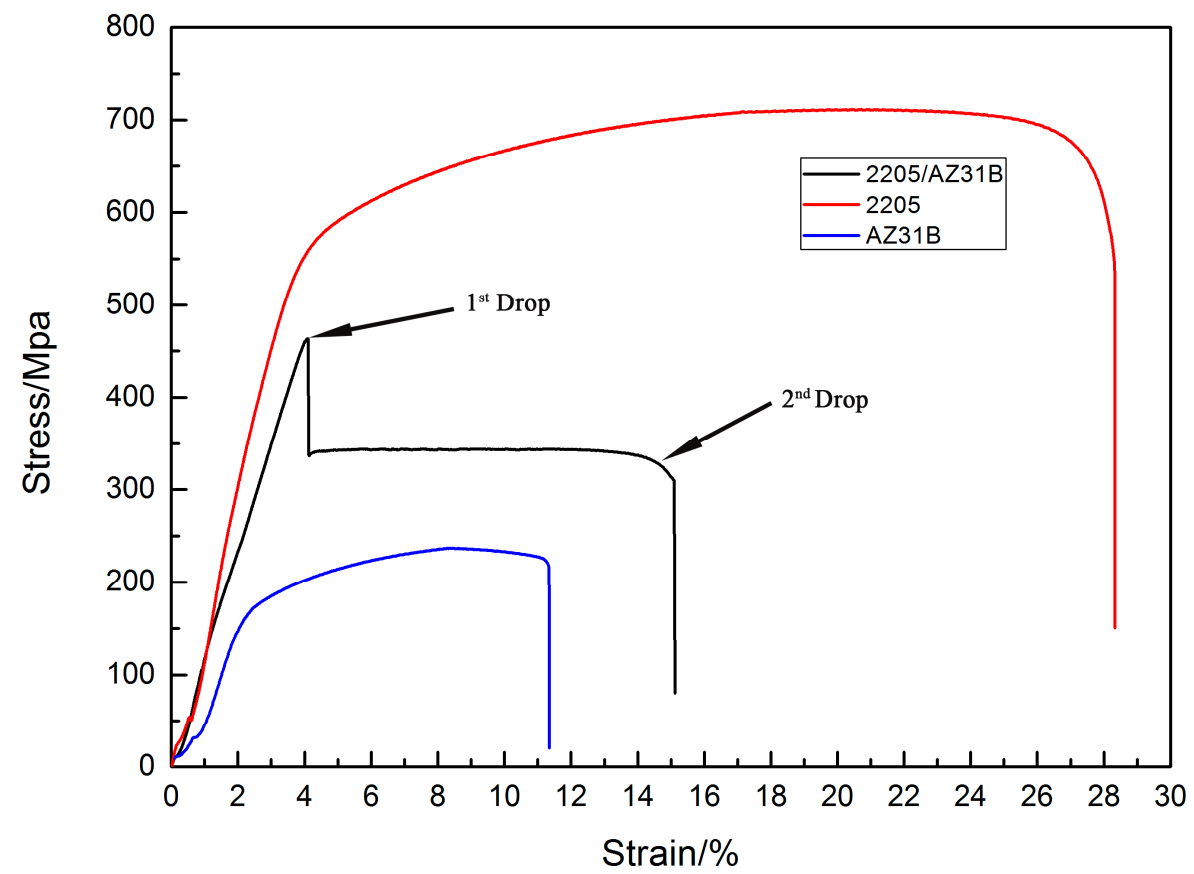

Figure 11. Stress-strain curves for tensile strength tests for 2205, 2205/AZ31B and AZ31B.

Table 4. Tensile strength test outcome.

\begin{tabular}{cccc}
\hline Material & Yield Strength (Mpa) & Ultimate Tensile Strength (Mpa) & Elongation (\%) \\
\hline 2205 base metal & 560.6 & 716.6 & 28.3 \\
AZ31B base metal & 160.75 & 237.9 & 11.6 \\
2205/AZ31B composite & - & 486.6 & 15.5 \\
\hline
\end{tabular}
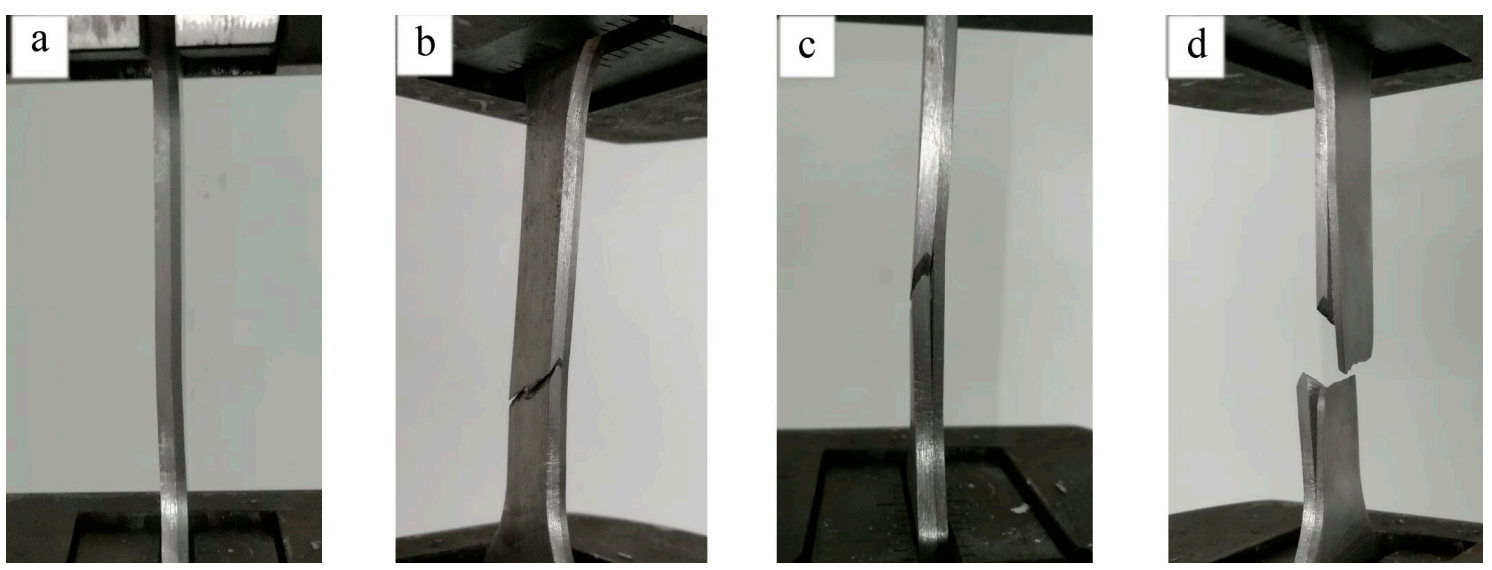

Figure 12. Photograph of tensile process. (a) Tensile initiation, (b) Fracture of magnesium alloy, (c) Interface separation and (d) Fracture of stainless steel.

The fracture scanning was undertaken to clarify the rupture mechanisms of composite materials. The fractograph following the tensile test is shown in Figure 13. Clearly, the fractograph of the 2205 side exhibits a typical ductile fracture showing deep equiaxed dimples (Figure 13a), which confirm excellent plasticity of duplex stainless steel. As seen in Figure 13b, cleavage fracture can be discerned since there is a clear cleavage plane in the tensile fracture surface of the Mg layer, which is in conformity with the smaller elongation of AZ31B magnesium alloy. 

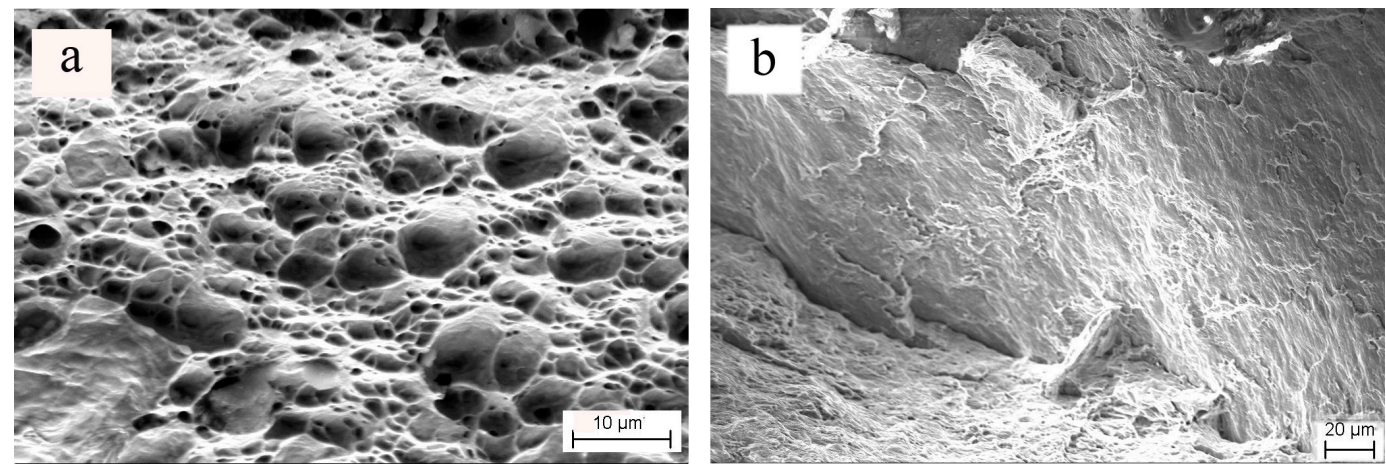

Figure 13. Scanning electron microscope (SEM) fractograph following tensile test. (a) 2205 side, (b) AZ31B side.

\subsection{Tensile Shear Test}

Tensile shear tests were conducted for the 2205/AZ31B composite sheet to check the bond strength of interface. Figure 14 shows the typical load-displacement curve obtained from the tensile shear test of 2205/AZ31B composite sheet. The specimens before and after the tensile shear test are presented in Figure 15. The tensile shear test specimen was found to be fractured along the interface between 2205 and AZ31B. The average tensile shear fracture strength was $105.63 \mathrm{MPa}$.

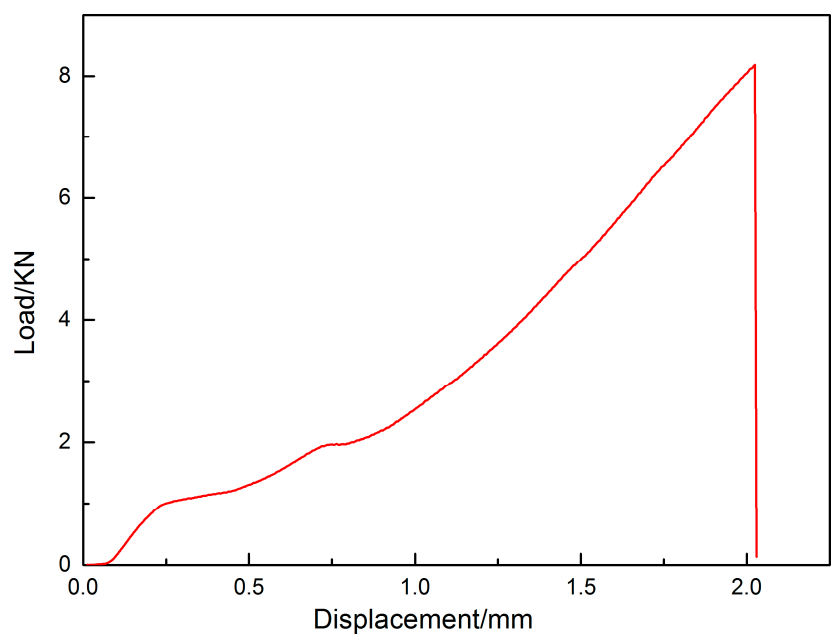

Figure 14. Load-displacement curve of 2205/AZ31B composite plate for tensile shear test.

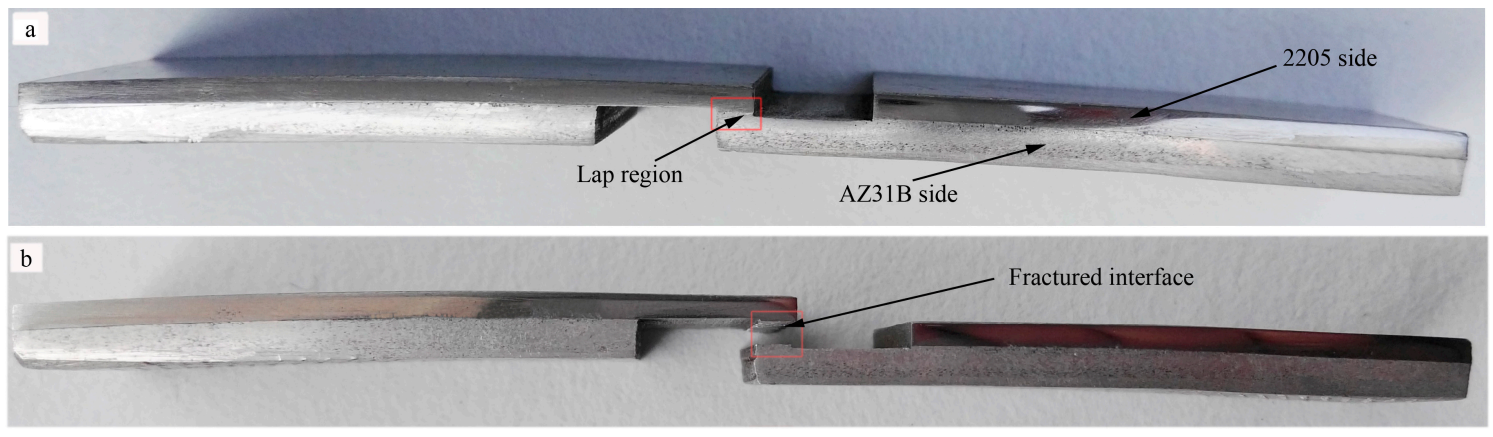

Figure 15. Specimens, (a) before tensile shear test and (b) after tensile shear test. 
Figure 16 displays the macroscopic morphology of fracture surfaces of tensile shear test. According to this figure, the morphology of fracture surfaces on both sides appeared periodic characteristics along the direction of detonation, which was attributed to the effect of variations in the velocity distribution at collision point and periodic disturbances of materials [38]. This is consistent with the less regular wavy interface as shown in Figure 7.
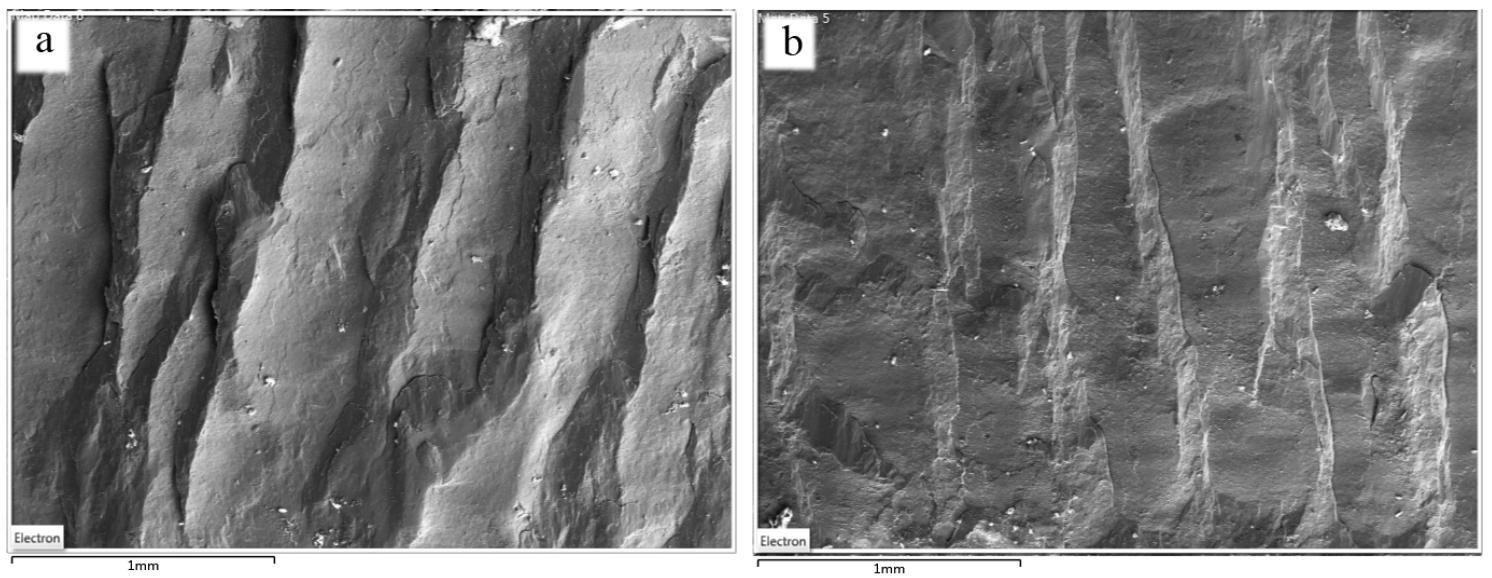

Figure 16. Scanning electron microscope (SEM) images of tensile shear fracture surface, (a) AZ31B side and (b) 2205 side.

\section{Conclusions}

(1) Explosive welding is a feasible technique to manufacture 2205/AZ31B composite plates.

(2) The interface of 2205/AZ31B bimetallic composite has a less regular wavy morphology, with locally melted pockets. Adiabatic shear bands occurred only in the AZ31B side near explosive welding interface. The microstructure observed with EBSD showed a strong refinement near the interface zones.

(3) Elemental mutual diffusion results in metallurgical bonding between 2205 duplex stainless steel and AZ31B magnesium alloy.

(4) The microhardness value near the interface was higher than the original value, attributed to the violent plastic deformation and grain refinement at the collision interface.

(5) The tensile shear strength of the bonding interface of 2205/AZ31B composite was 105.63MPa. Tensile strength of 2205/AZ31B composite material was higher than the base AZ31B.

Acknowledgments: This work is supported by the National Natural Science Foundation of China (No. 51275332), and the Natural Science Foundation of Shanxi Province (No. 201601D011036).

Author Contributions: Zhisheng Wu conceived and designed the experiments; Yan Li performed the experiments and wrote the paper.

Conflicts of Interest: The authors declare no conflict of interest.

\section{References}

1. Findik, F. Recent developments in explosive welding. Mater. Des. 2011, 32, 1081-1093. [CrossRef]

2. Zhang, L.J.; Pei, Q.; Zhang, J.X.; Bi, Z.Y.; Li, P.C. Study on the microstructure and mechanical properties of explosive welded 2205/X65 bimetallic sheet. Mater. Des. 2014, 64, 462-476. [CrossRef]

3. Mousavi, S.A.A.A.; Sartangi, P.F. Experimental investigation of explosive welding of cp-titanium/AISI 304 stainless steel. Mater. Des. 2009, 30, 459-468. [CrossRef]

4. Fronczek, D.M.; Wojewoda-Budka, J.; Chulist, R.; Sypien, A.; Korneva, A.; Szulc, Z.; Schell, N.; Zieba, P. Structural properties of Ti/Al clads manufactured by explosive welding and annealing. Mater. Des. 2016, 91, 80-89. [CrossRef] 
5. Luo, A.A. Magnesium: Current and potential automotive applications. JOM 2002, 54, 42-48. [CrossRef]

6. Li, D.; Chen, F.; Xie, Z.H.; Shan, S.; Zhong, C.J. Enhancing structure integrity and corrosion resistance of Mg alloy by a two-step deposition to avoid F etching to nano-SiO2, reinforcement. J. Alloys Compd. 2017, 705, 70-78. [CrossRef]

7. Kaya, Y.; Kahraman, N. An investigation into the explosive welding/cladding of Grade A ship steel/AISI 316L austenitic stainless steel. Mater. Des. 2013, 52, 367-372. [CrossRef]

8. Lee, K.S.; Kim, J.S.; Jo, Y.M.; Lee, S.E.; Heo, J.; Chang, Y.W.; Lee, Y.S. Interface-correlated deformation behavior of a stainless steel-Al-Mg 3-ply composite. Mater. Charact. 2013, 75, 138-149. [CrossRef]

9. Guo, Q.; Guo, X.; Wang, F.; Wang, Y.; Du, K. Micro-Arc Oxidized Corrosion Resistant Interlayer on Magnesium Alloy with Electromagnetic Wave Absorption Coatings. ECS Electrochem. Lett. 2012, 1, C13-C16. [CrossRef]

10. Mukai, T.; Mohri, T.; Mabuchi, M.; Nakamura, M.; Ishikawa, K.; Higashi, K. Experimental study of a structural magnesium alloy with high absorption energy under dynamic loading. Scr. Mater. 1998, 39, 1249-1253. [CrossRef]

11. Darwin, J.D.; Lal, D.M.; Nagarajan, G. Optimization of cryogenic treatment to maximize the wear resistance of 18\% Cr martensitic stainless steel by Taguchi method. J. Mater. Process. Technol. 2008, 195, 241-247. [CrossRef]

12. Nayeb-Hashemi, A.A.; Clark, J.B.; Swartzendruber, L.J. The Fe-Mg (Iron-Magnesium) system. J. Phase Equilib. 1985, 6, 235-238. [CrossRef]

13. Elthalabawy, W.; Khan, T. Liquid Phase Bonding of 316L Stainless Steel to AZ31 Magnesium Alloy. J. Mater. Sci. Technol. 2011, 27, 22-28. [CrossRef]

14. Bikulčius, G.; Miečinskas, P.; Ručinskienè, A.; Grigucevičienè, A.; Selskis, A.; Pakštas, V. Improvement of corrosion resistance of magnesium alloy by sputter coating with stainless steel. Trans. Inst. Met. Finish. 2012, 90, 125-128. [CrossRef]

15. Yuan, X.J.; Sheng, G.M.; Luo, J.; Jia, L.I. Microstructural characteristics of joint region during diffusion-brazing of magnesium alloy and stainless steel using pure copper interlayer. Trans. Nonferr. Met. Soc. China 2013, 23, 599-604. [CrossRef]

16. Miao, Y.; Han, D.; Yao, J.; Li, F. Effect of laser offsets on joint performance of laser penetration brazing for magnesium alloy and steel. Mater. Des. 2010, 31, 3121-3126. [CrossRef]

17. Wei, Y.; Li, J.; Xiong, J.; Huang, F.; Zhang, F. Microstructures and mechanical properties of magnesium alloy and stainless steel weld-joint made by friction stir lap welding. Mater. Des. 2012, 33, 111-114. [CrossRef]

18. Zhu, B.; Liang, W.; Li, X. Interfacial microstructure, bonding strength and fracture of magnesium-aluminum laminated composite plates fabricated by direct hot pressing. Mater. Sci. Eng. A 2011, 528, 6584-6588. [CrossRef]

19. Yan, Y.B.; Zhang, Z.W.; Shen, W.; Wang, J.H.; Zhang, L.K.; Chin, B.A. Microstructure and properties of magnesium AZ31B-aluminum 7075 explosively welded composite plate. Mater. Sci. Eng. A 2010, 527, 2241-2245. [CrossRef]

20. Acarer, M.; Gülenç, B.; Findik, F. The influence of some factors on steel/steel bonding quality on there characteristics of explosive welding joints. J. Mater. Sci. 2004, 39, 6457-6466. [CrossRef]

21. Zheng, Y. Explosive Welding and Metallic Composite and Their Engineering Application; Central South University Press: Changsha, China, 2002.

22. Mastanaiah, P.; Reddy, G.M.; Prasad, K.S.; Murthy, C.V.S. An investigation on microstructures and mechanical properties of explosive cladded C103 niobium alloy over C263 nimonic alloy. J. Mater. Process. Technol. 2014, 214, 2316-2324. [CrossRef]

23. Lysak, V.I.; Kuzmin, S.V. Lower boundary in metal explosive welding. Evolution of ideas. J. Mater. Process. Technol. 2012, 212, 150-156. [CrossRef]

24. Durgutlu, A.; Gülenç, B.; Findik, F. Examination of copper/stainless steel joints formed by explosive welding. Mater. Des. 2005, 26, 497-507. [CrossRef]

25. Follansbee, P.S.; Murr, L.E.; Staudhammer, K.P.; Meyers, M.A. Metallurgical Applications of Shock Wave and High Strain Rate Phenomena; Marcel Dekker, Inc.: New York, NY, USA, 1986; p. 451.

26. Yang, Y.; Xinming, Z.; Zhenghua, L.; Qingyun, L. Adiabatic shear band on the titanium side in the Ti/mild steel explosive cladding interface. Acta Mater. 1996, 44, 561-565. [CrossRef] 
27. Yang, Y.; Wang, B.F.; Hu, B.; Hu, K.; Li, Z.G. The collective behavior and spacing of adiabatic shear bands in the explosive cladding plate interface. Mater. Sci. Eng. A 2005, 398, 291-296. [CrossRef]

28. Zhang, N.; Wang, W.; Cao, X.; Wu, J. The effect of annealing on the interface microstructure and mechanical characteristics of AZ31B/AA6061 composite plates fabricated by explosive welding. Mater. Des. 2015, 65, 1100-1109. [CrossRef]

29. Xia, H.B.; Wang, S.G.; Ben, H.F. Microstructure and mechanical properties of Ti/Al explosive cladding. Mater. Des. 2014, 56, 1014-1019. [CrossRef]

30. Loureiro, A.; Mendes, R.; Ribeiro, J.B.; Leal, R.M.; Galvão, I. Effect of explosive mixture on quality of explosive welds of copper to aluminium. Mater. Des. 2016, 95, 256-267. [CrossRef]

31. Grignon, F.; Benson, D.; Vecchio, K.S.; Meyers, M.A. Explosive Welding of Aluminum to Aluminum: Analysis, Computations and Experiments; American Institute of Physics: Melville, NY, USA, 2004; pp. 1333-1351.

32. Song, J.; Kostka, A.; Veehmayer, M.; Raabe, D. Hierarchical microstructure of explosive joints: Example of titanium to steel cladding. Mater. Sci. Eng. A 2011, 528, 2641-2647. [CrossRef]

33. Xu, W.; Chen, D.L.; Liu, L.; Mori, H.; Zhou, Y. Microstructure and mechanical properties of weld-bonded and resistance spot welded magnesium-to-steel dissimilar joints. Mater. Sci. Eng. A 2012, 537, 11-24. [CrossRef]

34. Elthalabawy, W.M.; Khan, T.I. Microstructural development of diffusion-brazed austenitic stainless steel to magnesium alloy using a nickel interlayer. Mater. Charact. 2010, 61, 703-712. [CrossRef]

35. Manikandan, P.; Lee, J.O.; Mizumachi, K.; Mori, A.; Raghukandan, K.; Hokamoto, K. Underwater explosive welding of thin tungsten foils and copper. J. Nucl. Mater. 2011, 418, 281-285. [CrossRef]

36. Honarpisheh, M.; Asemabadi, M.; Sedighi, M. Investigation of annealing treatment on the interfacial properties of explosive-welded $\mathrm{Al} / \mathrm{Cu} / \mathrm{Al}$ multilayer. Mater. Des. 2012, 37, 122-127. [CrossRef]

37. Kim, I.K.; Hong, S.I. Roll-Bonded Tri-Layered Mg/Al/Stainless Steel Clad Composites and their Deformation and Fracture Behavior. Metall. Mater. Trans. A 2013, 44, 3890-3900. [CrossRef]

38. Mousavi, S.A.A.A.; Al-Hassani, S.T.S. Finite element simulation of explosively-driven plate impact with application to explosive welding. Mater. Des. 2008, 29, 1-19. [CrossRef]

(C) 2017 by the authors. Licensee MDPI, Basel, Switzerland. This article is an open access article distributed under the terms and conditions of the Creative Commons Attribution (CC BY) license (http:/ / creativecommons.org/licenses/by/4.0/). 